\title{
Is Regular Screening for Intracranial Aneurysm Necessary in Patients with Autosomal Dominant Polycystic Kidney Disease? A Systematic Review and Meta-analysis
}

\author{
Zien Zhou ${ }^{\text {a }}$ Ying Xub,c Candice Delcourt ${ }^{\text {b,d }}$ Jiehui Shan ${ }^{\mathrm{e}}$ Qiang Li $^{\text {b }}$ \\ Jianrong $\mathrm{Xu}^{\mathrm{a}}$ Maree L. Hackett ${ }^{\mathrm{b}, \mathrm{c}}$ \\ a Department of Radiology, Ren Ji Hospital, School of Medicine, Shanghai Jiao Tong University, Shanghai, China; \\ bThe George Institute for Global Health, University of New South Wales, ' Sydney Medical School, University of \\ Sydney, and dDepartment of Neurology, Royal Prince Alfred Hospital, Sydney, Australia; ' Department of Geriatrics, \\ South Campus, Ren Ji Hospital, School of Medicine, Shanghai Jiao Tong University, Shanghai, China
}

\section{Keywords \\ Intracranial aneurysm · Autosomal dominant polycystic kidney disease · Follow-up study · Magnetic resonance angiography}

\begin{abstract}
Background: The prevalence of intracranial aneurysm in patients with autosomal dominant polycystic kidney disease (ADPKD) is higher than that among the general population. We performed a systematic review and meta-analysis on the prevalence and natural history of intracranial aneurysm among patients with ADPKD. Methods: Medline, Embase, Web of Science and Scopus, from inception to July 2016, were searched for studies reporting the occurrence of intracranial aneurysms among participants with ADPKD. Two authors independently assessed the eligibility of all retrieved studies and extracted data. Information on the prevalence of intracranial aneurysms and their natural history in participants with ADPKD was collected from all included studies. Results: Fifteen studies with 1,490 participants with ADPKD were pooled to study about the prevalence of intracranial
\end{abstract}

aneurysm in participants with ADPKD, and the prevalence rate was found to be $10 \%$ (95\% Cl 7-13\%). Studies from China, Japan and Europe (Germany, Poland) reported a higher prevalence of intracranial aneurysm. Having a family history of haemorrhagic stroke or intracranial aneurysm was a risk factor for aneurysm occurrence. Twenty-three percent (95\% Cl 15-31\%) of the participants had multiple aneurysms. Most of the aneurysms were small $(<6 \mathrm{~mm})$ and located in the anterior circulation. Five studies with 171 participants (83 with 106 aneurysms at baseline and 88 without) were analyzed to understand the natural history of aneurysms, with an incidence of aneurysm growth, new aneurysm and aneurysm rupture of $1.84 \%$ (followed up for 435 personyears), $0.57 \%$ (1,227 person-years) and $0.13 \%$ (792 personyears) respectively. Conclusions: Screening for intracranial aneurysm is recommended in patients with ADPKD when there is a family history of haemorrhagic stroke or intracranial aneurysm and when they are from China, Japan or Europe (Germany, Poland). Based on existing data, regular imaging follow-up is not supported. High-quality, prospective studies are needed in the future.

(c) 2017 S. Karger AG, Basel

\section{KARGER}

(c) 2017 S. Karger AG, Basel

E-Mail karger@karger.com

www.karger.com/ced
Zien Zhou, MD

Department of Radiology

Ren Ji Hospital, School of Medicine, Shanghai Jiao Tong University

160 Pujian Road, Shanghai 200127 (China)

E-Mail julian_zze@ hotmail.com 


\section{Introduction}

Autosomal dominant polycystic kidney disease (ADPKD) is one of the most common hereditary diseases affecting approximately 1 in 400 to 1 in 1,000 individuals [1], and the fourth commonest cause of kidney failure globally [2]. Mutations in the PKD1 gene (located on chromosome 16 , accounting for $85 \%$ of cases) or in the PKD2 gene (located on chromosome 4, accounting for $15 \%$ of cases) lead to the dysfunction of corresponding proteins (polycystin 1 and 2), resulting in fluid accumulation and cyst formation in the kidneys $[1,3]$. The disease is clinically silent till adulthood with patients with PKD2 mutations having a milder phenotype than patients with PKD1 mutation.

ADPKD is associated with major extra-renal complications including the formation of cysts in other organs (liver, pancreas, seminal vesicle), cardiac valve disease and intracranial aneurysm. The prevalence of intracranial aneurysm in patients with ADPKD is higher than that among the general population (9-12 vs. $2-3 \%$ ), and aneurysm rupture causing subarachnoid or intracerebral haemorrhage is among the most serious complications of ADPKD [4]. The risk factors for aneurysm growth and rupture in the general population include large size, multiple aneurysms, location (posterior circulation), irregular shape, female gender, hypertension, smoking status, prior aneurysm rupture and ethnicity [5-9]. However, little is known about the natural history of intracranial aneurysm in patients with ADPKD. This contributes to the absence of official standardized recommendations for screening for, and management of, intracranial aneurysms in patients with ADPKD. In this systematic review and meta-analysis, we provide an overview of the prevalence and natural history of intracranial aneurysms (unruptured unless specified) among patients with ADPKD.

\section{Methods}

\section{Search Strategy}

The Preferred Reporting Items for Systemic Reviews and MetaAnalyses statement [10] was followed. The protocol was registered with PROSPERO international prospective register of systematic reviews (CRD42016046351). We searched Medline, Embase, Web of Science and Scopus databases from inception to July 2016. Our search strategy was based on the combination of the following medical subject headings terms or keywords: ("Intracranial Aneurysm" OR "Aneurysm, Ruptured” OR "aneurysm*” OR "cerebral aneurysm*”) AND ("Polycystic Kidney, Autosomal Dominant" OR "Polycystic Kidney Diseases” OR “ADPKD” OR "polycystic kidney") (online suppl. material; for all online suppl. material, see www.karger.com/doi/10.1159/000476073). There was no language restriction. Reference lists of all retrieved studies were crosschecked for further relevant studies until no further publications were found.

\section{Eligibility Criteria}

We included observational studies (prospective, retrospective and cross-sectional) reporting the occurrence of intracranial aneurysms among patients with ADPKD. The method of diagnosis of intracranial aneurysms was reported explicitly using imaging modalities such as magnetic resonance angiography (MRA), CT angiography, or digital subtraction angiography/cerebral angiography. We excluded the following: (1) studies with fewer than 5 ADPKD participants; (2) studies on treatment, genetics and molecular mechanisms of intracranial aneurysm; (3) studies on participants with autosomal recessive polycystic kidney disease; (4) animal studies, autopsy studies, simulation studies or mathematical models; (5) reviews, editorials, letters, conference abstracts, case or case series reports, guidelines, technical notes and book chapters.

If the same population was presented in more than one publication, the article that included the largest sample or the longest follow-up was included. We judged articles to be from the same cohort if they met the following criteria: there was evidence of overlapping recruitment sites, study dates, grant funding numbers, and similar or identical reported patient characteristics. Since we intended to explore whether screening for intracranial aneurysm and regular imaging follow-up are necessary for patients with ADPKD and mainly focused on those without neurological symptoms or history of neurological diseases, participants with a history of ruptured intracranial aneurysm, subarachnoid hemorrhage (SAH), or surgical intervention of ruptured intracranial aneurysm (endovascular coiling or neurosurgical clipping) were excluded if possible. We also excluded data from participants with the following conditions: (1) vascular malformations other than aneurysm; (2) intracranial fusiform aneurysm, dissecting aneurysm or arterial dolichoectasia. The National Institute of Health (NIH) quality assessment tool for observational cohort and cross-sectional studies was used for the assessment of methodological quality of included studies [11].

\section{Data Extraction}

Two authors (Z.Z. and Y.X.) reviewed all retrieved articles and extracted data independently. Title and abstracts were first screened to identify potentially eligible articles, and then full texts were read to confirm inclusion. Extracted data included the following information: (1) first author, year of publication, country or region, study design, and sample size; (2) patient characteristics such as age, gender, family history of haemorrhagic stroke or intracranial aneurysm (ruptured or un-ruptured), hypertension, smoking status, renal dysfunction, presence of liver cyst, and proportion of patient with intracranial aneurysm in the study population; (3) aneurysm imaging characteristics such as number of aneurysms per participant, location (middle cerebral artery (MCA), anterior cerebral artery or anterior communicating artery (ACA or ACoA), internal carotid artery (ICA), anterior circulation, posterior circulation), and aneurysm size ( $<3,<6,5-10,>10 \mathrm{~mm}) ;(4)$ data informing the natural history of intracranial aneurysm including follow-up imaging modality, mean or cumulative length of follow-up, number of participants over time (at recruitment, with aneurysm growth, new aneurysm or aneurysm rupture and 
Fig. 1. Flowchart of literature search. IA, intracranial aneurysm.

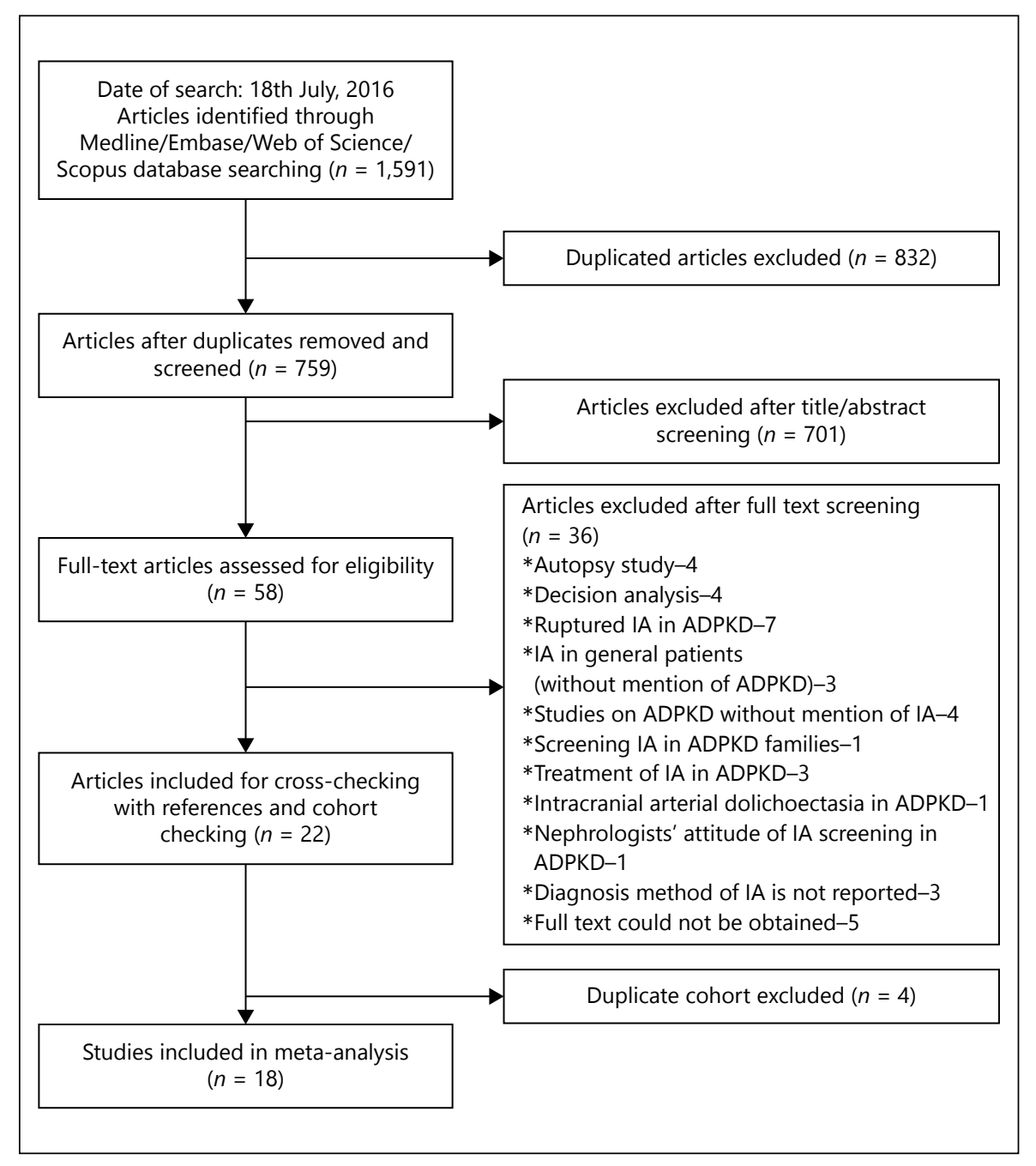

lost to follow-up). The extracted data was cross-checked and any disagreements were resolved by discussion or in consultation with a third author (M.L.H.). We contacted the authors of the original publication for any missing data.

\section{Statistical Analysis}

The prevalence and characteristics of intracranial aneurysms in participants with ADPKD were pooled using a random-effects model. The prevalence or risk ratios were reported with $95 \%$ CIs. Similarly to previous reviews $[12,13]$, aneurysm was chosen as the unit of observation for analysis of location and size. For the quantitative analysis of the natural history of aneurysm during follow-up, we multiplied the number of participants by the average length of follow-up to obtain the total number of personyears of follow-up if cumulative follow-up years were not reported. To estimate the prevalence of aneurysm growth, new aneurysm or aneurysm rupture per person-years, the number of participants with subsequent aneurysm growth, new aneurysm or aneurysm rupture was divided by the total number of personyears (or cumulative follow-up years). Heterogeneity among studies was assessed using the $I^{2}$ statistics. An $I^{2}$ value of 25, 50, and $75 \%$ was regarded as low, moderate and high heterogeneity respectively. Subgroup analysis was performed to understand the prevalence of intracranial aneurysm according to study design, region or country and whether all participants received brain imaging for intracranial aneurysm in prospective or retrospective studies. Where there was a high likelihood of differences, sensitivity analyses were performed excluding individual studies to determine reasons for the differences.

\section{Results}

\section{Study Selection and Characteristics}

We included 18 studies [14-31] in this review after excluding 4 articles with same cohorts [32-35] (Fig. 1). The full text of one included study written in Japanese [21] was translated into English by a clinical researcher at the George Institute for Global Health who comes from 
Table 1. The overview of the natural history of intracranial aneurysm in participants with ADPKD in 5 included studies

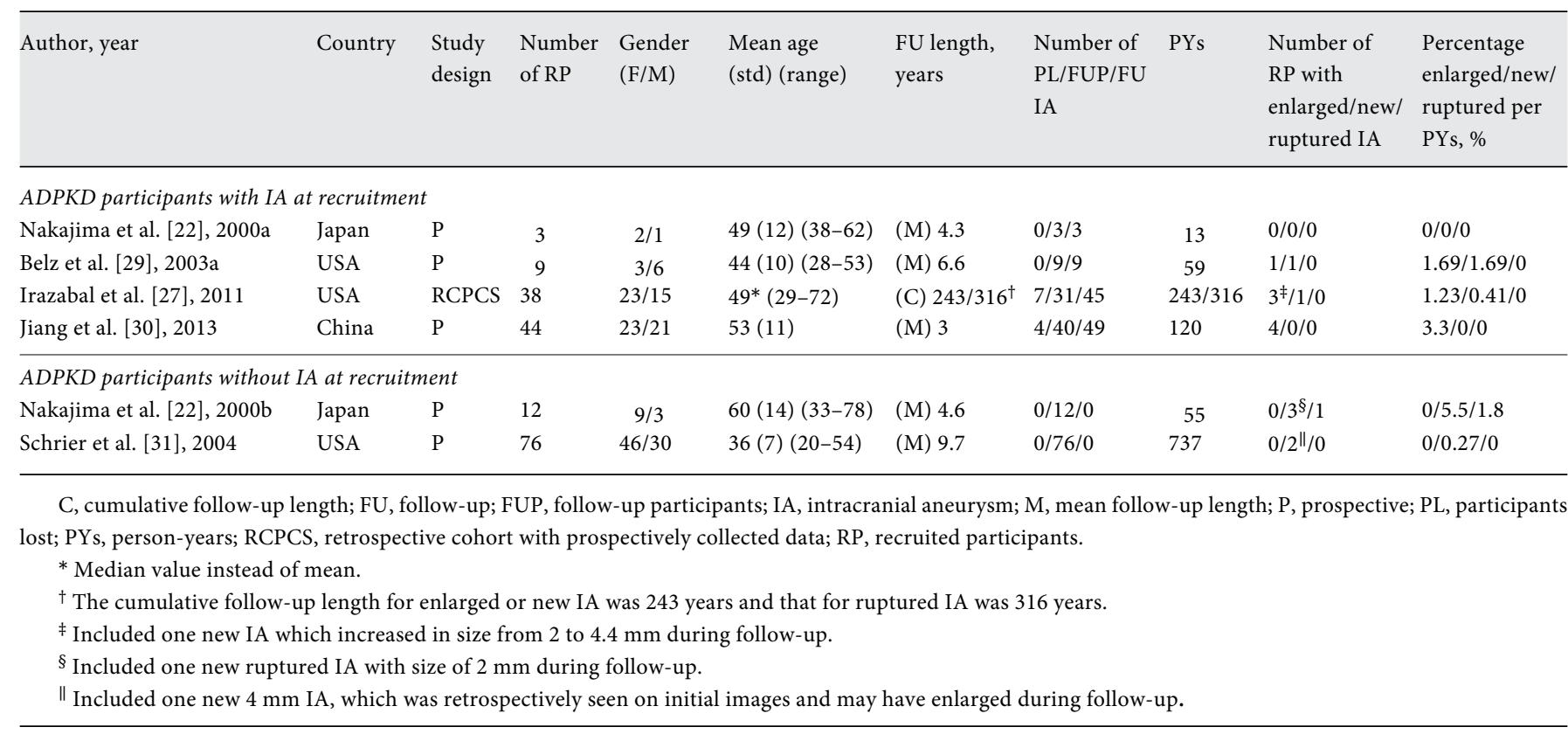

Japan. Fifteen studies with 1,490 participants with ADPKD were analyzed for the prevalence of intracranial aneurysm (online suppl. Table I), of which 11 studies with 171 aneurysms were pooled based on aneurysm characteristics (online suppl. Table II). Five studies with 171 participants with ADPKD were analyzed to gain information on the natural history of aneurysm (Table 1). NIH quality assessment characteristics are shown in online supplementary Table III with many studies exhibiting a high risk of bias.

\section{Results of Meta-Analysis}

The pooled prevalence of intracranial aneurysm in participants with ADPKD was $10 \%$ (95\% CI 7-13\%) with moderate heterogeneity $\left(I^{2}=72 \%\right)$ (Fig. 2$)$. The pooled prevalence of aneurysm according to aneurysm characteristics among ADPKD participants with aneurysm is shown in Table 2. Twenty-three percent (95\% Cl 15-31\%) of participants with intracranial aneurysms had multiple aneurysms. The aneurysm location was reported for 171 aneurysms from 11 cohorts. Sixteen percent $(95 \% \mathrm{Cl}$ $8-24 \%$ ) of aneurysms were located in the posterior circulation, while others were located in the anterior circulation $38 \%, 95 \% \mathrm{Cl} 29-48 \%$ in $\mathrm{MCA} ; 17 \%, 95 \% \mathrm{Cl} 12-23 \%$ in ACA or ACoA; $40 \%, 95 \% \mathrm{Cl} 8-72 \%$ in ICA). The aneurysm size was reported for 156 aneurysms from 8 cohorts. The pooled prevalence of aneurysm according to size was
$17 \%$ (95\% CI 3-31\%) (for diameters $<3 \mathrm{~mm}$ ), $83 \%$ (95\% CI 72-95\%) (<6 mm), 28\% (95\% CI 16-40\%) (5-10 mm) and $7 \%(95 \%$ CI $0-22 \%)(>10 \mathrm{~mm})$. The risk factors for aneurysm prevalence in participants with ADPKD are shown in Table 3. Those with a family history of haemorrhagic stroke or intracranial aneurysm (ruptured or unruptured) were 2.33 (95\% CI 1.60-3.38) times more likely to have an aneurysm than those without.

Four cohorts included 83 participants with ADPKD (with 106 aneurysms identified at baseline) followed for 508 person-years (Table 1). Two cohorts included 88 participants with ADPKD (without aneurysm at baseline) followed for 792 person-years. Seven participants with $\operatorname{ADPKD}(0.57 \%$ per person-years) had a new intracranial aneurysm during 1,227 person-years, including $2(0.46 \%)$ among participants with aneurysm at baseline (followed up for 435 person-years), and $5(0.63 \%)$ among those without aneurysm at baseline (followed up for $792 \mathrm{pa}$ tient-years). Eight (1.84\%) had aneurysms growth during 435 person-years and 1 person without aneurysm at baseline had a new ruptured aneurysm $(0.13 \%)$ during 792 person-years.

\section{Subgroup Analysis and Sensitivity Analysis}

The subgroup analysis on the prevalence of intracranial aneurysm in participants with ADPKD is shown in Table 4 . The pooled prevalence was highest in 2 cross- 
Table 2. The pooled prevalence of intracranial aneurysm according to aneurysm characteristics

\begin{tabular}{|c|c|c|c|c|c|}
\hline & Number of studies & $\begin{array}{l}\text { Included studies } \\
\text { (reference number) }\end{array}$ & $\begin{array}{l}\text { Number of } \\
\text { aneurysms }\end{array}$ & Prevalence, \% (95\% CI) & Heterogeneity $I^{2}, \%$ \\
\hline With multiple IA & 9 & $14-16,18,21,23,26-28$ & - & $23(15-31)$ & 13 \\
\hline MCA & 9 & $14,16,18,21,23,24,26-28$ & 61 & $38(29-48)$ & 29 \\
\hline $\mathrm{ACA}$ or $\mathrm{ACoA}$ & 10 & $14,16,18,21-24,26-28$ & 32 & $17(12-23)$ & 0 \\
\hline ICA $^{*}$ & 11 & $14-16,18,21-24,26-28$ & 64 & $40(8-72)$ & 98 \\
\hline \multicolumn{6}{|l|}{ IA size $(\mathrm{mm})^{\ddagger}$} \\
\hline$<3$ & 5 & $16,18,26-28$ & 34 & $17(3-31)$ & 90 \\
\hline$<6$ & 8 & $16,18,21-23,26-28$ & 124 & $83(72-95)$ & 83 \\
\hline $5-10$ & 8 & $16,18,21-23,26-28$ & 39 & $28(16-40)$ & 61 \\
\hline$>10$ & 2 & 23,26 & 3 & $7(0-22)$ & 50 \\
\hline
\end{tabular}

ACA or ACoA, anterior cerebral artery or anterior communicating artery; IA, intracranial aneurysm; ICA*, internal carotid artery (including the junction between internal carotid artery and posterior communicating artery); MCA, middle cerebral artery; P-Cir, posterior circulation.

${ }^{\dagger}$ Eleven studies with 171 IA were included for analysis of location.

‡ Eight studies with 156 IA were included for analysis of size. Total IA is more than 156 because of partial overlap between size $<6$ and $5-10$ $\mathrm{mm}$.

Fig. 2. Meta-analysis of the prevalence of intracranial aneurysm in participants with ADPKD by years of publication.

\begin{tabular}{|c|c|c|c|c|}
\hline Study & Sample size & & $\begin{array}{c}\text { Prevalence, \% } \\
(95 \% \mathrm{Cl})\end{array}$ & $\begin{array}{c}\text { Weight } \\
\%\end{array}$ \\
\hline Wakabayashi, 1983 [14] & 17 & $\longrightarrow$ & $41(18,65)$ & 1.55 \\
\hline Matsumura, 1986 [15] & 5 & $\longrightarrow$ & $60(17,100)$ & 0.50 \\
\hline Chapman, 1992 [16] & 92 & $\boldsymbol{n}^{\prime}$ & $4(0,9)$ & 10.29 \\
\hline Higashihara, 1992 [17] & 75 & -1 & $8(2,14)$ & 8.46 \\
\hline Ruggieri, 1994 [18] & 93 & + & $9(3,14)$ & 8.87 \\
\hline Torra, 1996 [19] & 166 & $\boldsymbol{\square}$ & $3(0,6)$ & 11.60 \\
\hline Konoshita, 1998 [20] & 11 & : & $27(1,54)$ & 1.26 \\
\hline lida, 1998 [21] & 30 & $\frac{1}{1-1}$ & $13(1,25)$ & 4.31 \\
\hline Nakajima, 2000 [22] & 15 & - & $20(0,40)$ & 1.99 \\
\hline Graf, 2002 [23] & 43 & in & $14(4,24)$ & 5.26 \\
\hline Romão, 2006 [24] & 42 & -1 & $7(0,15)$ & 7.05 \\
\hline Rabbani, 2008 [25] & 56 & $=$ & $4(0,8)$ & 9.65 \\
\hline$X u, 2011[26]$ & 355 & 1 & $12(9,16)$ & 10.94 \\
\hline Irazabal, 2011 [27] & 407 & 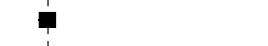 & $9(7,12)$ & 11.43 \\
\hline Niemczyk, 2013 [28] & 83 & - & $17(9,25)$ & 6.84 \\
\hline Overall & 1,490 & \langle & $10(7,13)$ & 100.00 \\
\hline \multirow[t]{2}{*}{ (Heterogeneity $\mathrm{I}^{2}=72 \%$ ) } & & & \multicolumn{2}{|c|}{ (Random effects analysis) } \\
\hline & & $\begin{array}{lllll}0 & 20 & 40 & 60 & 80\end{array}$ & & \\
\hline
\end{tabular}

sectional studies from Japan (39\%, 95\% CI 8-70\%). The pooled prevalence was lower in retrospective studies than in prospective studies $(4 \%, 95 \%$ CI $1-6 \%$ vs. $11 \%, 95 \%$ CI 8-14\%). For prospective studies, the prevalence of intracranial aneurysm in Europe (Germany, Poland) (16\%,
95\% CI 9-22\%) and Asia (Japan, China) (17\%, 95\% CI $8-26 \%)$ was higher than that in the United States $(8 \%$, $95 \%$ CI $4-11 \%$ ). One of the 3 retrospective studies and all studies with prospective recruitment performed brain imaging for intracranial aneurysm in all participants, 
Table 3. Risk ratio of intracranial aneurysm presence in participants with ADPKD

\begin{tabular}{|c|c|c|c|c|}
\hline & $\begin{array}{l}\text { Number } \\
\text { of studies }\end{array}$ & $\begin{array}{l}\text { Included studies } \\
\text { (reference number) }\end{array}$ & Risk ratio $(95 \% \mathrm{CI})$ & Heterogeneity $I^{2}, \%$ \\
\hline \multicolumn{5}{|l|}{ Gender } \\
\hline Female & 11 & $14-16,18,21-24,26-28$ & Reference & - \\
\hline Male & 11 & $14-16,18,21-24,26-28$ & $1.13(0.82-1.55)$ & 0 \\
\hline \multicolumn{5}{|l|}{ Age, years } \\
\hline$\geq 40$ & 5 & $16,22,26-28$ & $2.07(0.79-5.40)$ & 53 \\
\hline$\geq 60$ & 4 & $22,26-28$ & $1.88(0.52-6.70)$ & 63 \\
\hline $\mathrm{FH}$ & 6 & $15,16,18,22,26,27$ & $2.33(1.60-3.38)$ & 0 \\
\hline Hypertension & 5 & $14,18,21,26,28$ & $0.86(0.53-1.39)$ & 0 \\
\hline Smoking* & 1 & 27 & $1.12(0.61-2.05)$ & - \\
\hline Renal dysfunction & 4 & $18^{\dagger}, 21^{\ddagger}, 26^{\dagger}, 28^{\S}$ & $1.45(0.92-2.28)$ & 0 \\
\hline
\end{tabular}

Table 4. Subgroup analysis for the prevalence of intracranial aneurysm in participants with ADPKD

\begin{tabular}{|c|c|c|c|c|c|}
\hline Prospective and RCPCS & 10 & $14,16,18,21-24,26-28$ & 1,177 & $11(8-14)$ & 59 \\
\hline Retrospective & 3 & $17,19,25$ & 297 & $4(1-6)$ & 10 \\
\hline Cross-sectional & 2 & 15,20 & 16 & $39(8-70)$ & 38 \\
\hline USA & 3 & $16,18,27$ & 592 & $8(4-11)$ & 50 \\
\hline Europe (Germany, Poland) & 2 & 23,28 & 126 & $16(9-22)$ & 0 \\
\hline Asia (Japan, China) & 4 & $14,21,22,26$ & 417 & $17(8-26)$ & 52 \\
\hline \multicolumn{6}{|c|}{$\begin{array}{l}\text { Brain imaging in all participants } \\
\quad \text { (prospective, RCPCS and Retrospective) }\end{array}$} \\
\hline Yes & 11 & $14,16^{*}, 17,18,21-24,26-28$ & 1,248 & $10(8-13)$ & 51 \\
\hline
\end{tabular}

NR, not reported; RCPCS, retrospective cohort with prospectively collected data.

* Four of 92 participants were excluded from analyses because of incomplete IA screening due to technical failure or occurrence of adverse reactions.

with the pooled prevalence of $10 \%$ (95\% CI 8-13\%). Sensitivity analyses were performed on the prevalence of aneurysm located in the ICA and with small size $(<3,<6$ $\mathrm{mm}$; online suppl. Table IV). After removing 2 studies (one with all 4 detected aneurysms located in the ICA, the other with only 1 out of the 18 aneurysm located in the ICA) $[15,28]$, the prevalence of aneurysm located in the
ICA was 39\% (95\% CI 30-47\%) with low heterogeneity $\left(I^{2}=6 \%\right)$. After removing one study with all 8 detected aneurysms with size $<6 \mathrm{~mm}$ [16], the prevalence of aneurysm with size $<6 \mathrm{~mm}$ was $81 \%$ (95\% CI 73-89\%) with low heterogeneity $\left(I^{2}=19 \%\right)$. The heterogeneity for the prevalence of aneurysm with size $<3 \mathrm{~mm}$ was still high in sensitivity analyses. 


\section{Discussion}

Our systematic review showed that the prevalence of intracranial aneurysm in patients with ADPKD was $10 \%$ (95\% CI 7-13\%). Having a family history of haemorrhagic stroke or intracranial aneurysm (ruptured or unruptured) was the only factor associated with a significantly higher prevalence of intracranial aneurysm in patients with ADPKD. While there was an elevated prevalence of aneurysm in participants $\geq 40$ years of age, male and with renal dysfunction, this was not statistically significant. Being hypertensive, smoking and having liver cysts had no effect on the prevalence of aneurysm, but the results for the latter 2 should be treated with caution due to the small number of cohorts.

We included more cohorts in our review than 2 previous systematic reviews $[12,13]$. Two studies [36, 37] (included in Vlak et al. [12]) were excluded from our review because the diagnosis of aneurysm was based on autopsy or surgery. Another [38] was excluded because the study population included families rather than individual patients with ADPKD. Our pooled prevalence was consistent with Rinkel et al. [13] (10\%, 95\% CI 6.2-15\%), but more precise (narrower CI). The heterogeneity among studies of prevalence was moderate. Two retrospective studies $[19,25]$ may have underestimated the prevalence of aneurysm, since brain imaging may not have been completed for all participants. In prospective studies, there may have been a bias towards recruiting participants with suspected aneurysm or a high risk of developing one. In all prospective and cross-sectional studies, the prevalence was higher in participants with ADPKD from Asia and Europe than that from the United States, which may indicate geographic or population difference.

Most of the aneurysms in our systematic review were located in the anterior circulation, consistent with Vlak et al. [12] results in the general population (18\% in ACA and branches, $35 \%$ in MCA). However, there was high heterogeneity for the prevalence of aneurysm located in the ICA. The extreme results of one small study from Japan [15] and one prospective study from Poland [28] accounted for some of the heterogeneity. Small aneurysms $(<6 \mathrm{~mm})$ were more prevalent among patients with ADPKD than in the general population $(72 \%, 95 \%$ CI $68-77)$ [13]. The sources of heterogeneity for the prevalence of tiny aneurysms $(<3$ $\mathrm{mm}$ ) remain unclear. In our opinion, the improvements in imaging technology over the years may have enhanced the capability of detecting intracranial aneurysm. In addition, different imaging modalities adopted among studies may have also affected the detection of tiny aneurysms.
To the best of our knowledge, this is the first systematic review on the natural history of intracranial aneurysm in patients with ADPKD. Compared to the general population $[5,6]$, a smaller proportion of aneurysm grow or rupture (growth: $1.84 \%$ per person-years in patients with ADPKD vs. $9 \%$ per person-years in general population; rupture: 0.13 vs. $0.6-1.3 \%$ per person-years). The sole ruptured aneurysm in our review was from a 33-year-old man with negative MRA at recruitment, who developed SAH at 10 months due to rupture of a 2-mm saccular aneurysm [22]. The risk of developing a new aneurysm during follow-up was also low, making frequent imaging follow-up unnecessary for patients with ADPKD and intracranial aneurysm.

This systematic review has the following limitations: (1) the lack of individual participants' data did not allow us to conduct multivariable analyses on the risk factors for intracranial aneurysm presence; (2) the limited number of studies (5) on the natural history of intracranial aneurysm is not enough for management recommendations and assessment of risk factors for aneurysm growth, new aneurysm or aneurysm rupture; (3) full texts were not available for 5 articles and 2 of the 5 articles were not written in English, which might introduce potential bias.

Based on our systematic review, screening for aneurysm in patients with ADPKD is more relevant when there is a family history of haemorrhagic stroke or intracranial aneurysm (ruptured or un-ruptured), and when patients are from China, Japan or Europe (Germany, Poland). Regular imaging follow-up is not recommended due to a low prevalence of aneurysm growth, new aneurysm and aneurysm rupture. Since existing data on the natural history of intracranial aneurysm in patients with ADPKD is limited, additional high-quality, prospective studies are needed to develop management recommendations.

\section{Acknowledgments}

This research was supported by a research grant from Shanghai Health and Family Planning Commission (No. 20144Y0119) and the National Nature Science Foundation of China (No. 81571630). Maree L. Hackett holds a National Heart Foundation Future Leader Fellowship, Level 2 (100034, 2014-2017). The authors would like to acknowledge staff at the University of Sydney Medical Library, for their help developing the search strategy for this review. The authors would like to acknowledge Dr. Sohei Yoshimura for translating one paper written in Japanese.

\section{Disclosure Statement}

None. 


\section{References}

1 Chebib FT, Torres VE: Autosomal dominant polycystic kidney disease: core curriculum 2016. Am J Kidney Dis 2016;67:792-810.

2 Ong AC, Devuyst O, Knebelmann B, Walz G: Autosomal dominant polycystic kidney disease: the changing face of clinical management. Lancet 2015;385:1993-2002.

3 Simms RJ: Autosomal dominant polycystic kidney disease. BMJ 2016;352:i679.

4 Perrone RD, Malek AM, Watnick T: Vascular complications in autosomal dominant polycystic kidney disease. Nat Rev Nephrol 2015; 11:589-598.

5 Backes D, Rinkel GJ, Laban KG, Algra A, Vergouwen MD: Patient- and aneurysm-specific risk factors for intracranial aneurysm growth: a systematic review and meta-analysis. Stroke 2016;47:951-957.

6 Wermer MJ, van der Schaaf IC, Algra A, Rinkel GJ: Risk of rupture of unruptured intracranial aneurysms in relation to patient and aneurysm characteristics: an updated metaanalysis. Stroke 2007;38:1404-1410.

7 Juvela S, Poussa K, Porras M: Factors affecting formation and growth of intracranial aneurysms: a long-term follow-up study. Stroke 2001;32:485-491.

8 Matsubara S, Hadeishi H, Suzuki A, Yasui N, Nishimura $\mathrm{H}$ : Incidence and risk factors for the growth of unruptured cerebral aneurysms: observation using serial computerized tomography angiography. J Neurosurg 2004; 101:908-914.

9 Wiebers DO, Whisnant JP, Huston J 3rd, Meissner I, Brown RD Jr, Piepgras DG, Forbes GS, Thielen K, Nichols D, O'Fallon WM, Peacock J, Jaeger L, Kassell NF, Kongable-Beckman GL, Torner JC; International Study of Unruptured Intracranial Aneurysms Investigators: Unruptured intracranial aneurysms: natural history, clinical outcome, and risks of surgical and endovascular treatment. Lancet 2003;362:103-110.

10 Moher D, Liberati A, Tetzlaff J, Altman DG: Preferred reporting items for systematic reviews and meta-analyses: the PRISMA Statement. Open Med 2009;3:e123-e130.

$11 \mathrm{http} / / /$ www.nhlbi.nih.gov/health-pro/guidelines/in-develop/cardiovascular-risk-reduction/tools/cohort.

12 Vlak MH, Algra A, Brandenburg R, Rinkel GJ: Prevalence of unruptured intracranial aneurysms, with emphasis on sex, age, comorbidity, country, and time period: a systematic review and meta-analysis. Lancet Neurol 2011; 10:626-636.

13 Rinkel GJ, Djibuti M, Algra A, van Gijn J Prevalence and risk of rupture of intracranial aneurysms: a systematic review. Stroke 1998; 29:251-256

14 Wakabayashi T, Fujita S, Ohbora Y, Suyama T, Tamaki N, Matsumoto S: Polycystic kidney disease and intracranial aneurysms. Early angiographic diagnosis and early operation for the unruptured aneurysm. J Neurosurg 1983; 58:488-491.

15 Matsumura M, Wada H, Nojiri K, Ohwada A, Shinoda T: Unruptured intracranial aneurysms in polycystic kidney disease. Acta Neurochir (Wien) 1986;79:94-99.

16 Chapman AB, Rubinstein D, Hughes R, Stears JC, Earnest MP, Johnson AM, Gabow PA, Kaehny WD: Intracranial aneurysms in autosomal dominant polycystic kidney disease. $\mathrm{N}$ Engl J Med 1992;327:916-920.

17 Higashihara E, Aso Y, Shimazaki J, Ito H, Koiso K, Sakai O: Clinical aspects of polycystic kidney disease. J Urol 1992;147:329332.

18 Ruggieri PM, Poulos N, Masaryk TJ, Ross JS, Obuchowski NA, Awad IA, Braun WE, Nally J, Lewin JS, Modic MT: Occult intracranial aneurysms in polycystic kidney disease: screening with MR angiography. Radiology 1994;191:33-39.

19 Torra R, Badenas C, Darnell A, Nicolau C, Volpini V, Revert L, Estivill X: Linkage, clinical features, and prognosis of autosomal dominant polycystic kidney disease types 1 and 2 . J Am Soc Nephrol 1996;7:2142-2151.

20 Konoshita T, Okamoto K, Koni I, Mabuchi H: Clinical characteristics of polycystic kidney disease with end-stage renal disease. The Kanazawa Renal Disease Study Group. Clin Nephrol 1998;50:113-117.

21 Iida H, Naito T, Hondo H, Demachi H, Aoki S: [Intracranial aneurysms in autosomal dominant polycystic kidney disease detected by MR angiography: screening and treatment]. Nihon Jinzo Gakkai Shi 1998;40:4247.

22 Nakajima F, Shibahara N, Arai M, Gohji K, Ueda $\mathrm{H}$, Katsuoka $\mathrm{Y}$ : Intracranial aneurysms and autosomal dominant polycystic kidney disease: followup study by magnetic resonance angiography. J Urol 2000;164:311-313.

23 Graf S, Schischma A, Eberhardt KE, Istel R, Stiasny B, Schulze BD: Intracranial aneurysms and dolichoectasia in autosomal dominant polycystic kidney disease. Nephrol Dial Transplant 2002;17:819-823.

24 Romão EA, Moysés Neto M, Teixeira SR, Muglia VF, Vieira-Neto OM, Dantas M: Renal and extrarenal manifestations of autosomal dominant polycystic kidney disease. Braz J Med Biol Res 2006;39:533-538.

25 Rabbani MA, Ali SS, Murtaza G, Ahmad B, Maria Q, Siddiqui BK, Shah SM, Ahmad A: Clinical presentation and outcome of autosomal dominant polycystic kidney disease in Pakistan: a single center experience. J Pak Med Assoc 2008;58:305-309.

$26 \mathrm{Xu} \mathrm{HW}, \mathrm{Yu}$ SQ, Mei CL, Li MH: Screening for intracranial aneurysm in 355 patients with autosomal-dominant polycystic kidney disease. Stroke 2011;42:204-206.

27 Irazabal MV, Huston J 3rd, Kubly V, Rossetti S, Sundsbak JL, Hogan MC, Harris PC, Brown
RD Jr, Torres VE: Extended follow-up of unruptured intracranial aneurysms detected by presymptomatic screening in patients with autosomal dominant polycystic kidney disease. Clin J Am Soc Nephrol 2011;6:12741285.

28 Niemczyk M, Gradzik M, Niemczyk S, Bujko M, Gołębiowski M, Pączek L: Intracranial aneurysms in autosomal dominant polycystic kidney disease. AJNR Am J Neuroradiol 2013; 34:1556-1559.

29 Belz MM, Fick-Brosnahan GM, Hughes RL, Rubinstein D, Chapman AB, Johnson AM, McFann KK, Kaehny WD, Gabow PA: Recurrence of intracranial aneurysms in autosomal-dominant polycystic kidney disease. Kidney Int 2003;63:1824-1830.

30 Jiang T, Wang P, Qian Y, Zheng X, Xiao L, Yu S, Liu S: A follow-up study of autosomal dominant polycystic kidney disease with intracranial aneurysms using 3.0 $\mathrm{T}$ three-dimensional time-of-flight magnetic resonance angiography. Eur J Radiol 2013;82:18401845.

31 Schrier RW, Belz MM, Johnson AM, Kaehny WD, Hughes RL, Rubinstein D, Gabow PA: Repeat imaging for intracranial aneurysms in patients with autosomal dominant polycystic kidney disease with initially negative studies: a prospective ten-year follow-up. J Am Soc Nephrol 2004;15:1023-1028.

32 Huston J 3rd, Torres VE, Sulivan PP, Offord $\mathrm{KP}$, Wiebers DO: Value of magnetic resonance angiography for the detection of intracranial aneurysms in autosomal dominant polycystic kidney disease. J Am Soc Nephrol 1993;3:1871-1877.

33 Huston J 3rd, Torres VE, Wiebers DO, Schievink WI: Follow-up of intracranial aneurysms in autosomal dominant polycystic kidney disease by magnetic resonance angiography. J Am Soc Nephrol 1996;7:21352141.

34 Gibbs GF, Huston J 3rd, Qian Q, Kubly V, Harris PC, Brown RD Jr, Torres VE: Followup of intracranial aneurysms in autosomaldominant polycystic kidney disease. Kidney Int 2004;65:1621-1627.

35 Niemczyk M, Pilecki T, Gradzik M, Bujko M, Niemczyk S, Pączek L: Blood pressure and intracranial aneurysms in autosomal dominant polycystic kidney disease. Kidney Blood Press Res 2014;39:630-635.

36 Schievink WI, Torres VE, Piepgras DG, Wiebers DO: Saccular intracranial aneurysms in autosomal dominant polycystic kidney disease. J Am Soc Nephrol 1992;3:88-95.

37 Chan KW: Adult polycystic kidney disease in Hong Kong Chinese: an autopsy study. Pathology 1993;25:229-232.

38 Ronkainen A, Hernesniemi J, Puranen M, Niemitukia L, Vanninen R, Ryynänen M, Kuivaniemi H, Tromp G: Familial intracranial aneurysms. Lancet 1997;349:380-384. 